\title{
SOLID STATE CHARACTERIZATION OF A NOVEL PHYSICAL INTERACTION (PARACETAMOL- CHLORPHENIRAMINE MALEATE)
}

\author{
IYAN SOPYAN ${ }^{*}$, INTAN MUTIARA SARI ${ }^{1}$, INSAN SUNAN K. ${ }^{1}$
}

1Departement of Pharmaceutics and Pharmaceutical Technology, Faculty of Pharmacy, Universitas Padjadjaran Email: sopyan1os@gmail.com

Received: 29 Sep 2017, Revised and Accepted: 11 Nov 2017

\begin{abstract}
Objective: Interactions of active pharmaceutical ingredients (API) as well as pharmaceutical excipients don't occur in a pharmaceutical dosage form. Base on structures of paracetamol (PCT) and chlorphenamine maleate (CTM), its combination is possible to give a physical interaction in the solid state. This study was conducted to investigate the physical interaction of PCT and CTM in the solid state.

Methods: Characterization used the polarization microscope, solubility test, powder x-ray diffraction (PXRD) to observe peak shifting in $2 \Theta$ angle, and fourier transform infrared spectroscopy (FT-IR) to examine wavenumber shifting.

Results: Results of solubility exhibited an increased solubility percentage with increasing concentration. Polarization microscope analysis presented a combination of crystal morphology after the two substances were mixed in an equimolar ratio. The result of melting point determination of each pure substance was $172{ }^{\circ} \mathrm{C}$ for PCT, $132{ }^{\circ} \mathrm{C}$ for CTM, and $170{ }^{\circ} \mathrm{C}$ for the mixture of the two substances in various ratios. Diffractogram showed the shifting at angle 20: 20.715, 19.355-23.500 and 21.840, 26.455-20.330 for concentration ratio of PCT: CTM in (132:0.5) and (330:1) respectively and any change in the functional group was observed from infrared spectrum.
\end{abstract}

Conclusion: All evaluation of PCT and CTM in the solid state has exhibited the interaction in solid condition.

Keywords: Paracetamol, Chlorphenamine maleate, Polarization microscope, X-Ray diffraction, FT-IR

(C) 2018 The Authors. Published by Innovare Academic Sciences Pvt Ltd. This is an open access article under the CC BY license (http://creativecommons.org/licenses/by/4.0/) DOI: http://dx.doi.org/10.22159/ijap.2018v10i1.22840

\section{INTRODUCTION}

In the process of drug manufacturing, drug interactions in a solid state are very likely to occur, but it analyzes need time and cost. In the drug industry, it is a difficult thing to do and other more disturbing features are chemical physics interactions that may emit a profile that affects biological availability such as drug solubility and dissolution. Pharmaceutical preparations in general consist of two or more active ingredients and an excipient. Since a number of ingredients are present, it is essential to understand their mutual compatibility. Ideally, the mixture should have no interaction or only minimal reaction between the ingredients when they are mixed. In some cases, a chemical reaction between materials can occur spontaneously and the change can be easily observed. However, the physical interaction between some materials do not produce visible changes; sometimes these interactions take place gradually to affect the performance of the active ingredient (medicine) or in other words reduce its stability before its time [1]

Theoretically, physics interactions can be occurred in two or more similar material [2], its similarity included in the molecular formula, internal structure, crystal lattice symmetry and the level of energy in the second of such material [3]. Physics interactions that occur can be either complex formation, molecular compounds (co-crystalline) [4], solid or aqueous dispersions and solid. In this study, the mixed raw materials will be studied from a drug that is already widely used as anti-influenza, namely PCT and CTM [5-6].

In drugs, both drugs (PCT and CTM), it is possible there is a physical interaction involving the merger of the two active ingredients. The areas where intermolecular interactions occur and where this interaction does not occur depending on the transfer of charge from the respective structure of paracetamol and CTM [7]. Furthermore, when seen from the perspective of bonding interactions, both structures formed hydrogen bonds and Van der Waals bonding. Of the bonding interactions that occur between paracetamol and CTM, bonding develops potentially during the occurrence of physical interaction [8-9]. Compounds that can form this type of interaction include compounds that have the potential to form clusters of noncovalent bonding, such as hydrogen bonding, ionic bonding, and van der Waals forces [8]. In this work, we attempted to characterize the physical interaction that occurs with PCT-CTM which may affect the pharmaceutical profile of a drug. Unexpected interactions may decrease the potential of drugs in ensuring the expected drug effects.

\section{MATERIALS AND METHODS}

\section{Materials}

Paracetamol purity $>98$ purchase from Changshu Huagang Pharmaceutical Co., Ltd China, Chlorpheniramine Maleate (Farma), Potassium Bromide (Merck), Methanol 95\% (Merck).

\section{Equipment}

Polarization microscope (Olympus SC20 Cx31), melting point (biotech, UK), Spectrophotometry UV (Analytical Jena Specord 250), $\mathrm{X}$-ray powder diffraction analysis (Pan Analytical), fourier transform infrared (R-Prestige Shimadzu $®$ )

\section{Methods}

Observation on the morphology of crystal form of PCT, CTM, and mix both using polarization microscopes

PCT (1-3 mg) is dissolved in ethanol 95\% saturated aqueous solution is then to be dripped on the glass objects, allowed to crystallize. Then for CTM is dissolved in ethanol $95 \%$ and then melted on the top area of recrystallization of PCT with comparison equimolar. The result of the crystallization observed in the areas of contact between the crystals of PCT with saturated aqueous CTM. Physical interaction is observed by polarization microscopy at $100 \mathrm{x}$ magnification and recorded with a digital camera, using polarization microscope.

Determination of the melting point of CTM, PCT, and a mixture of both

Prepared samples of pure CTM, PCT, and a mixture of PCT and CTM sample by comparison mole (132:0.5), (9200:0.8), (330:1), $(400: 1.3)$, and $(500: 1.5)$. The mole comparison was prepared according to doses combination of PCT and CTM in the dosage form. After it crushed samples in advance to be smooth. Then the results of 
the grinding samples with a variety of different concentrations are incorporated into the glass capillary pipe with a height of $2.5 \mathrm{~mm}$ up to $3.5 \mathrm{~mm}$ after solid may be filled by way of tapping to taste on a solid surface. Then the capillary pipe which has been inserted into a sample filled-in electric melting point deciding set the temperature of its melting temperature, then melting point sample is seen from the start of the initial samples are fused until it dissolves completely. Melting point results obtained are then compared with the theoretical melting point of each substance using melting point apparatus [9].

\section{Determination of zero crossing using derivative spectro-} photometry UV-Vis

PCT and CTM weighed $1000 \mathrm{mg}$ and $10 \mathrm{mg}$, put in $50 \mathrm{ml}$ measuring flask, plus $2 \mathrm{ml}$ of methanol and aquadest up to $50 \mathrm{ml}$. Then from each substance is done dilution, adjusted for the dilution of the sample at each of the raw substances. From the solution curve of absorption have been made first and second overlay absorption curves for each of the substances. From these spectra have defined zero crossing of PCT and CTM by wavelength has a zero absorption [10] using Spectrophotometry UV.

\section{Preparation of PCT stock solution}

Accurately weigh of $100 \mathrm{mg}$ of PCT, then put into a measuring flask $50 \mathrm{ml}$, after it added $2 \mathrm{ml}$ of solvent methanol then was vacuumed for 15 min next added aquadest to mark the boundaries and was homogenized. Then prepared an initial concentration of 5 concentrations of $4 \mathrm{ppm}$ and then do as much dilution $2.02 .5 \mathrm{ppm}$, ppm $3.0 \mathrm{ppm}$, ppm and $3.54 .0 \mathrm{ppm}$. The next solution is the raw samples measured at $243 \mathrm{~nm}$ maximum wavelength and wavelength $246 \mathrm{~nm}$ [11].

\section{Preparation of CTM stock solution}

Accurately weighed CTM $10 \mathrm{mg}$, then put into a measuring flask 50 $\mathrm{ml}$, after it added $2 \mathrm{ml}$ of solvent methanol was sonicated for $15 \mathrm{~min}$, then added aquadest to mark the boundaries and homogenized. Then prepared initial concentration the concentration of $50.04 \mathrm{ppm}$ and then do as much dilution $0.005 \mu \mathrm{g} / \mathrm{ml}, 0.010 \mu \mathrm{g} / \mathrm{ml}, 0.015 \mu \mathrm{g} / \mathrm{ml}$, $0.020 \mu \mathrm{g} / \mathrm{ml}$, and $0.025 \mu \mathrm{g} / \mathrm{ml}$ in $20 \mathrm{ml}$ measuring flask. Next raw CTM solution is measured at a wavelength of maximum $264 \mathrm{~nm}$ and $243 \mathrm{~nm}[11]$.

\section{Assay of PCT and CTM}

Weighted sample mixed with comparison mole i.e. 132:0.5, 200:0.8, $330: 1,400: 1.3$, and 500:1.5. Then put in $50 \mathrm{ml}$ measuring flask, added $2 \mathrm{ml}$ methanol solvent and was vacuumed for $15 \mathrm{~min}$, then added aquadest to mark the boundary. Furthermore, the solution mixture measured at $243 \mathrm{~nm}$ wavelength and $264 \mathrm{~nm}$ with the derivatives zero crossing spectrophotometry method [12].

\section{Determination of sample concentration (PCT and CTM)}

The absorbance obtained from the results of each test sample, then put into the equation of calibration curve in accordance with the respective raw substances, after which it would have obtained the value of molar absorptivity. Its results obtained are used in the determination of the percentage of the sample levels.

\section{PXRD analysis of PCT and CTM and their mixture}

The diffractogram patterns obtained by X-ray powder diffraction analysis, as many as 5-10 mg of PCT, CTM, and sample the mixture of PCT and CTM by comparison mole 132:0.5, 200:0.8, 330:1, 400:1.3, and 500:1.5 at room temperature. Conditions of measurement as follows: target metals $\mathrm{Cu} \mathrm{K \alpha}$, filters, voltage $40 \mathrm{kV}$, a current of $40 \mathrm{~mA}$, an analysis was conducted on 2 thetas of $5-48^{\circ}$ at a constant image rate of $4 \% \mathrm{~min}$. The sample placed on sample holder and flattened to prevent particle orientation during the preparation of the sample [13].

\section{Fourier transform infrared (FT-IR) analysis (PCT, CTM, and mixed)}

Each pure substance PCT $100 \mathrm{mg}$ and $100 \mathrm{mg}$ and CTM substance a mixture of PCT and CTM weighed in mole comparison; 132:0.5, 200:0.8, 330:1, 400:1.3, and 500:1.5 was dispersed in potassium bromide (KBr), it's made by mixing a sample with a mass of $\mathrm{KBr}$, the infrared spectrum of results obtained with infrared spectrophotometry on a range of wavenumbers $400-4000 \mathrm{~cm}^{-1}[14]$ using fourier transform infrared.

\section{RESULTS AND DISCUSSION}

The result of polarization microscopy studies (fig. 1) showed the different shape and color of crystal between PCT-CTM and their physical mixture. It's also shown the existence of crystal morphology of the combined mixture with the equimolar comparison. Crystallization is a simple method to observe the identification between two components, especially drug compounds that are not stable on warming [15]. Each component of the compounds PCT and CTM have good solubility in ethanol [16].

Morphological observation of crystal form can be carried out using polarization microscopes after being dissolved with methanol. A mixed result indicated that the presence of sharp crystal form and a subtler form of crystal while the other differences from the combined PCT and CTM. Its indicates a difference in violet color and it also showed the presence of such a form of amorphous, and the blue colors, red, orange indicates the shape of the crystal.

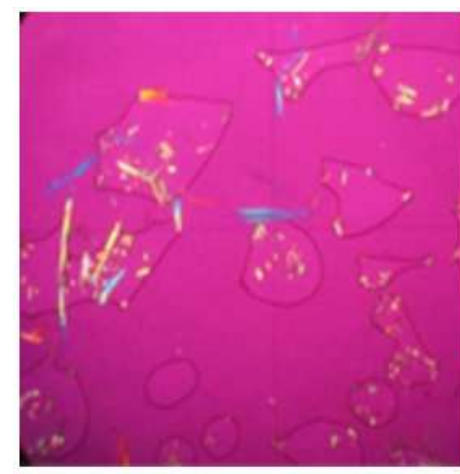

A

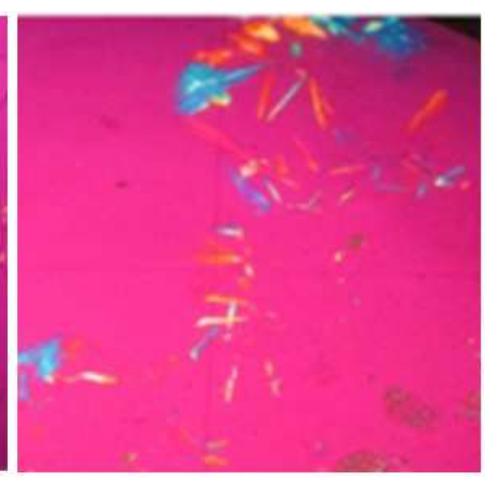

B

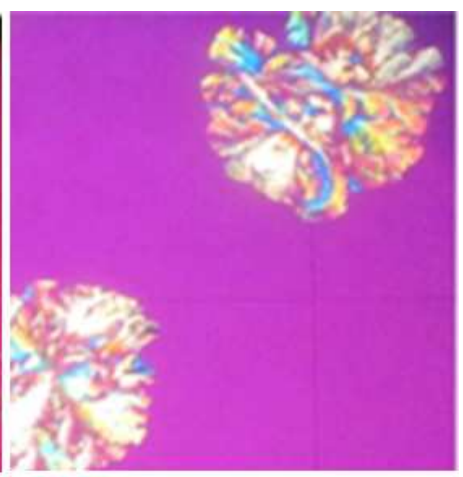

$\mathrm{C}$

Fig. 1: PCT (A), CTM (C), and their physical mixture (B)

The result of melting point test of PCT-CTM and several mixtures in different molar ratio presented in table 1 . The value of the table in mixture exhibited the melting point value in between of PCT and CTM purely. Tests of melting point showed that the raw material of PCT had a melting point of $172{ }^{\circ} \mathrm{C}$ in purely form. The raw materials that go into CTM had a melting point of $132{ }^{\circ} \mathrm{C}$. As for the mixed substance, the melting point was $170{ }^{\circ} \mathrm{C}$, a value closer to the melting point of PCT. the increasing or decreasing of melting point in the mixture was indicated the physical interaction of its constituent [1]. 
Table 1: Melting point of PCT, CTM (mole) and the mixture (mole ratio); mixture 1(132:0.5); mixture 2 (200: 0.8), mixture 3 (330:1), mixture 4 (400:1.3), and mixture 5 (500:1.5)

\begin{tabular}{lll}
\hline S. No. & Material & Melting point [ $\left.{ }^{\circ} \mathbf{C}\right]$ \\
\hline 1. & PCT & $172 \pm 0.2$ \\
2. & CTM & $132 \pm 0.3$ \\
3. & Mixture 1 & $170 \pm 0.2$ \\
4. & Mixture 2 & $170 \pm 0.2$ \\
5. & Mixture 3 & $170 \pm 0.2$ \\
6. & Mixture 4 & $170 \pm 0.3$ \\
7. & Mixture 5 & $170 \pm 0.3$ \\
\hline
\end{tabular}

Values was presented in mean $\pm \mathrm{SD}, \mathrm{n}=3$

Results of solubility test (fig. 2 and fig. 3) showed that increasing levels of percentage along with an increase in concentration levels on PCT pure and unadulterated CTM. The increasing value of solubility exhibited a possibility a synergies interaction between PCT and CTM [4]. The possibility mechanism of increasing solubility was caused by more intense interaction with water [17] or can also be supported to the $\mathrm{pH}$ changes that can lead to forming stable ion that very solvable in a water environment [18]. The results of the percent levels were obtained using the second derivative spectrophotometry [19].

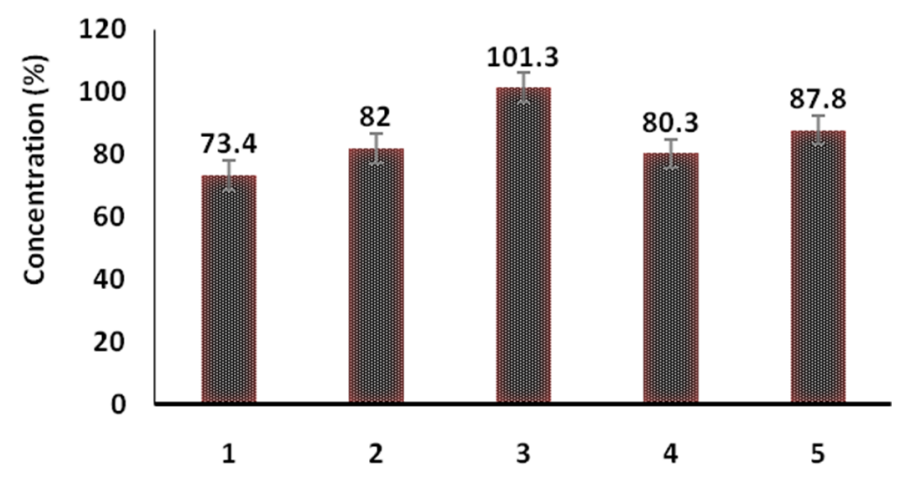

Fig. 2: Result of percentage paracetamol (mole) in the mixture (mole ratio) (mixture of PCT and CTM) 1= (132:0.5), 2= $(200: 0.8), 3=(330$ : 1), $4=(400: 1.3) 5=(500: 1.5)$ (values presented in mean $\pm S D, n=3)$

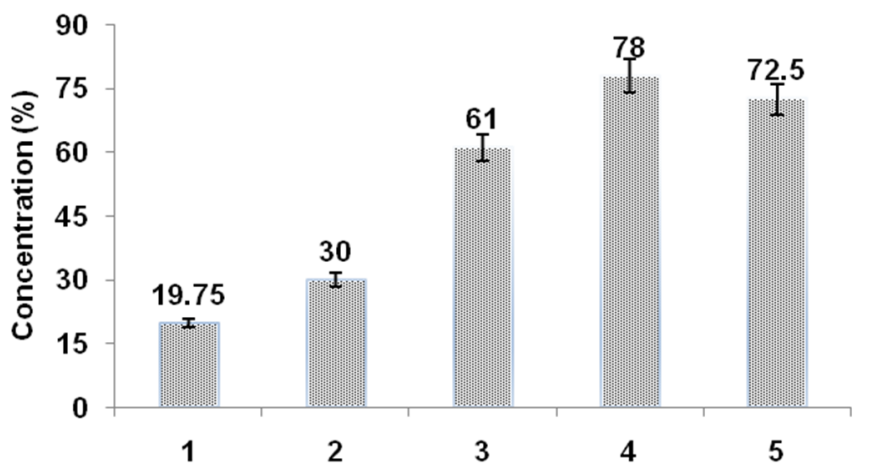

Fig. 3: Result of percentage CTM (mole) and it mixture (mole ratio) (mixture of PCT: CTM) 1= (132:0.5), 2= (200:0.8), 3= (330:1), 4= (400:1.3) $5=(500: 1.5)$ (values presented in $($ mean $\pm S D), n=3)$

Result of solubility test of PCT (fig. 2) presented an increasing maximum solubility in a physical mixture of PCT: CTM in a mole ratio (330:1). The increasing was risen up to $30 \%$, accordingly, its value was statistically significant ( $\mathrm{p}^{*}$ calculation $>0.05, \alpha=0.05$ ). Result test of CTM solubility (fig. 3) presented of the maximum increasing of CTM was achieved by the mixture with mole ratio of PCT and CTM (400:1.3) about $40 \%$ than mixture 1 . The interaction of the PCT and CTM in solid state has raised a value of solubility of both. It's contributed by the interaction of hydrogen bonding as interaction in cocrystal form [8].

Based on diffractogram (fig. 4), the following shifts were observed. For mole ratio PCT: CTM $=132: 0.5$, a shift was noticed at the top of the angle $2 \theta=20.15$ for PCT, 19.355 for CTM, and 23.50for their mixture. For the mole ratio PCT: CTM $=330: 1$ the shift was observed at the top of the angle $2 \theta=18.40$ for PCT, 20.30 for CTM, and 26.455 for their mixture. Similarly, for the mole ratio PCT: CTM $=500: 1.5$ shifting peak occurred at angle $2 \theta=16.535$ for PCT, 16.460 for CTM, and 18.22for their mixture. Further, for the mole ratios PCT: CTM = 200:0.8and 0.3: 400, not many changes in $2 \theta$ occurred but a significant shift of CTM was observed. The shifting of diffractogram has exhibited the interaction of material in solid state or changes of internal space group of molecular structure [20-21]. The result of diffractogram showed shifting for several peaks at $2 \theta$ angle, it showed the changes in space group of structural [14]. 


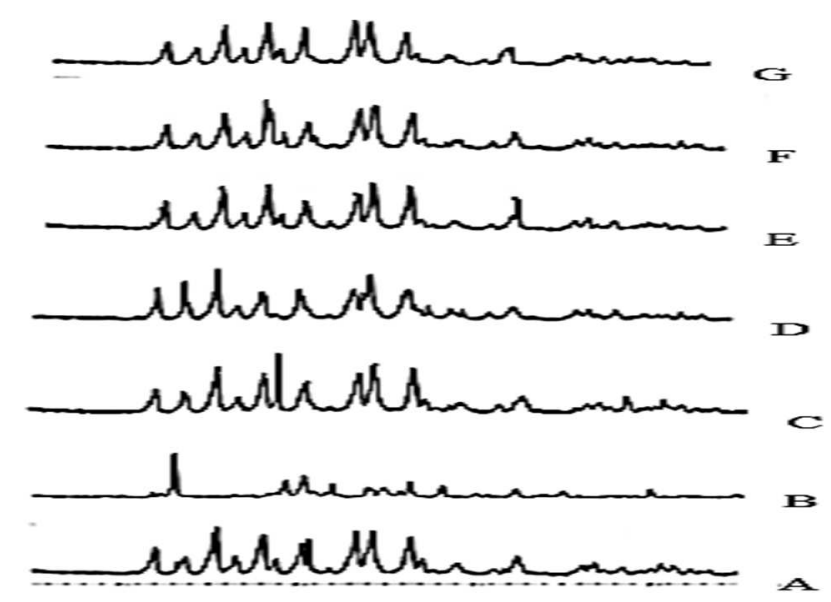

Fig. 4: Diffractogram of PCT (A), CTM (B), mixture of PCT: CTM (C-G)

FTIR spectrum (fig. 5) indicated a shifting on spectrum of CTM purely as compared to the CTM in the mixture, its tends to increase the intensity of the sharp, whereas in the un-diluted PCT tend intensity obtained PCT tends not to undergo much change in the intensity of its incorporation in spectrum [22]. The shifting of the wavenumber from spectrum exhibited the interaction in material in solid state [23]. Result of spectrum overlay from PCT, CTM and it mixture, it's exhibited the shifting of C-H stretching in $3000 \mathrm{~cm}^{-1}$ and $\mathrm{C}=0$ in wavelength $1760 \mathrm{~cm}^{-1}$.

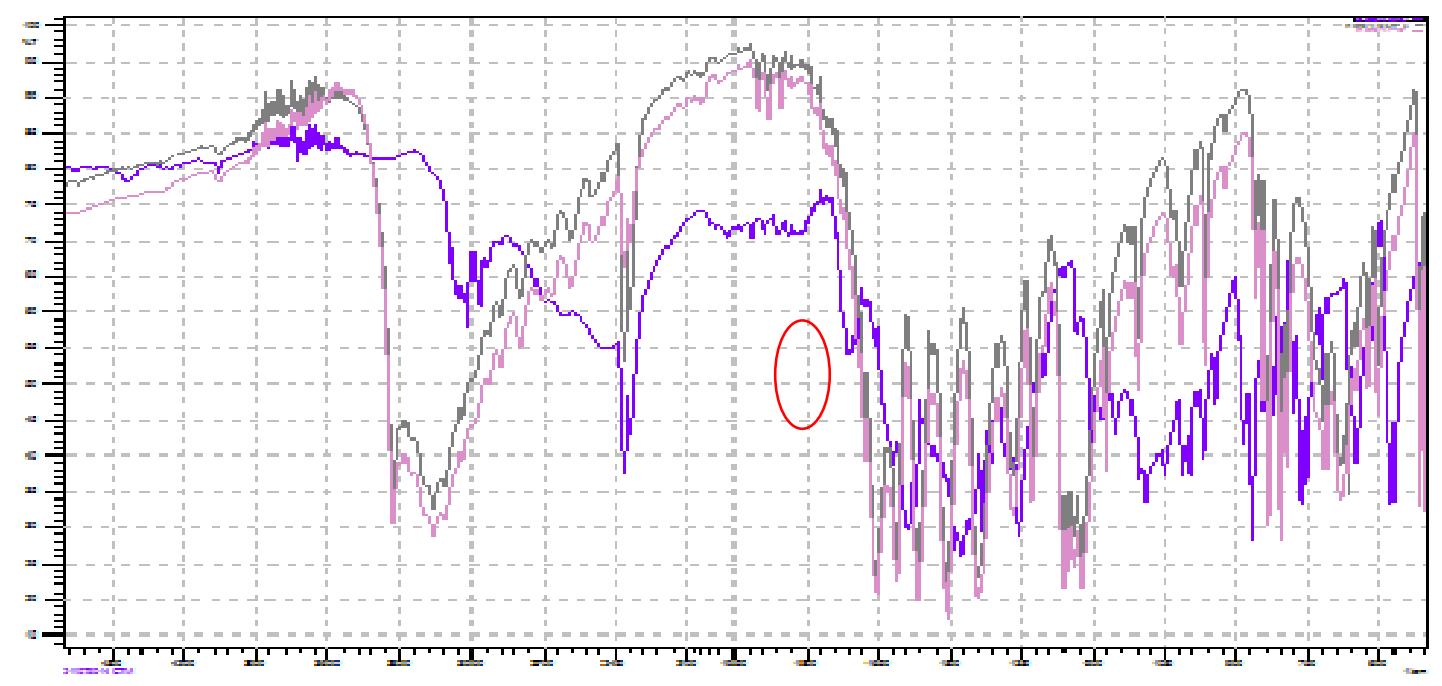

Fig. 5: FTIR Spectrum of PCT [-line], CTM [-line] dan mix of PCT-CTM [-line]

\section{CONCLUSION}

Physical interactions were observed between PCT and CTM. The changes were studied based on crystal morphology for a combination of PCT and CTM after both substances were mixed. The melting point of the mixture was observed to be close to the melting point of pure PCT at $170{ }^{\circ} \mathrm{C}$. Tests based on percent levels showed a rise in percent levels with increasing concentrations of the substance in the mixture. The XRDP peak shifting was observed at angle $2 \theta=20.715$. Further, 19.355 changed to 23.00 and 21.840 , and 26.45 changed to 20.330 for the mole ratio PCT: CTM $=132: 0.5$ and $330: 1$. Testing on the functional group using FTIR indicated the absence of a recently formed functional group.

\section{ABBREVIATION}

PCT: paracetamol, CTM: chlorpheniramine maleate, PXRD: powder $\mathrm{x}$-ray diffraction, FTIR: fourier transform infrared spectroscopy. SD: standard deviation

\section{ACKNOWLEDGEMENT}

The authors acknowledge of PT. Gracia Pharmindo for material supporting and Kemenristekdikti of Indonesia for founding.

\section{CONFLICT OF INTERESTS}

Declared non

\section{AUTHORS CONTRIBUTIONS}

All the authors have contributed equally.

\section{REFERENCES}

1. Zaini E. Identification of physical interaction between trimethoprim and sulfamethoxazole by contact method kofler and crystallization reaction. Indones J Pharm 2016;21:31-7.

2. Airaksinen S, Karjalainen M, Kivikero N, Westermarck S, Shevchenko A, Rantanen J, et al. Excipient selection can significantly affect solid-state phase transformation in formulation during wet granulation. AAPS PharmSciTech 2005;6:11-22.

3. Löbmann K, Strachan C, Grohganz H, Rades T, Korhonen O, Laitinen R. Co-amorphous simvastatin and glipizide combinations show improved physical stability without evidence of intermolecular interactions. Eur J Pharm Biopharm 2012;81:159-69.

4. Hiendrawan S, Hartanti AW, Veriansyah B, Widjojokusumo E, Tjandrawinata RR. Solubility enhancement of ketoconazole via salt and cocrystal formation. Int J Pharm Pharm Sci 2015;21:160-4. 
5. Nugrahani I, Asyarie S, Soewandhi SN, Ibrahim S. Solid state interaction between amoxicillin trihydrate and potassium Clavulanate. Malays J Pharm Sci 2007;5:45-57.

6. Putra OD, Nugrahani I, Ibrahim S, Uekusa H. Pembentukan padatan semi kristalin dan ko-kristal parasetamol. J Mat Sains 2013;17:83-8.

7. Maeno Y, Fukami T, Kawahata M, Yamaguchi K, Tagami T, Ozeki $\mathrm{T}$, et al. Novel pharmaceutical cocrystal consisting of paracetamol and trimethylglycine, a new promising cocrystal former. Int J Pharm 2014;473:179-86.

8. Sopyan I, Fudholi A, Muchtaridi M, Puspitasari I. A simple effort to enhance solubility and dissolution rate of simvastatin using co-crystallization. Int J Pharm Pharm Sci 2016;8:342-6.

9. S MB, Dengale SJ, Shenoy GG, Bhat K. Preparation, solid-state characterisation of paclitaxel and naringen cocrystals with improved solubility. Int J Appl Pharm 2016;8:32-7.

10. Nugrahani I, Ibrahim S, Puspita DD. Kristal biru2, 3 dimetil-Nfenilalanin (DNF) hasil interaksi kimia padatan asam mefenamat dengan asam oksalat. J Mat Sains 2013;17:98-104.

11. Departemen Kesehatan RI. Farmakope Indonesia Edisi IV. IV. Jakarta: Depertementkesehatan RI; 1995. p. 63,210,649.

12. Naid T, Kasim S, Pakaya M. Penetapan kadar parasetamoldalam tablet kombinasi parasetamoldengan kofein secaraspektofotometri ultraviolet sinar tampak. Univ Hasanudin Makasar 2011;15:77-82.

13. Sopyan I, Fudhloli A, Muchtaridi M, Sari IP, Permatasari D. A novel of derivative spectrophotometry as rapid and accurate method in application of simvastatin co-crystal assay. Int J Res Pharm Sci 2017;20:301-6.

14. Sopyan I, Fudholi A, Muchtaridi M, Sari IP. Simvastatinnicotinamide co-crystal: design, preparation and preliminary characterization. Trop J Pharm Res 2017;16:297-302.
15. Lin HL, Zhang GC, Lin SY. Real-time co-crystal screening and formation between indomethacin and saccharin via DSC analytical technique or DSC-FTIR microspectroscopy. J Therm Anal Calorim 2014;120:679-87.

16. Zaini E, Halim A, Sundani NS, Setyawan D. Peningkatan laju pelarutan trimetropim melalui metode ko-kristalisasidengan nikotinamida. J Farm Indones 2011;5:205-12.

17. Good DJ, Rodríguez-Hornedo N. Solubility advantage of pharmaceutical cocrystals. Cryst Growth Des 2009;9:225264.

18. Delori A, Galek PTA, Pidcock E, Patni M, Jones W. Knowledgebased hydrogen bond prediction and the synthesis of salts and cocrystals of the anti-malarial drug pyrimethamine with various drug and GRAS molecules. Cryst Eng Comm 2013; 15:2916-28.

19. Karpińska J. Derivative spectrophotometry-recent applications and directions of developments. Talanta 2004;64:801-22

20. Chadha R, Saini A, Arora P, Jain DS, Dasgupta A, Row TNG. Multicomponent solids of lamotrigine with some selected coformers and their characterization by thermoanalytical, spectroscopic and X-ray diffraction methods. Cryst Eng Comm 2011;13:6271-84.

21. Caira MR, Nassimbeni LR, Van Oudtshoorn B. X-ray structural characterization of anhydrous metronidazole benzoate and metronidazole benzoate monohydrate. J Pharm Sci 1993; 82:1006-9.

22. Alam MS, Lee DU. Spectral (FT-IR, FT-Raman, UV, and fluorescence), DFT, and solidstate interaction analyses of (E)-4(3,4-dimethoxybenzylideneamino)-1,5-dimethyl-2-phenyl-1Hpyrazol-3(2H)-one. J Mol Struct 2017;1128:174-85.

23. Brittain HG. Vibrational spectroscopic studies of co-crystals and salts. 3. cocrystal products formed by benzene carboxylic acids and their sodium salts. Cryst Growth Des 2010;10:373-90. 